\title{
Permanent Magnet Brushless Drives
}

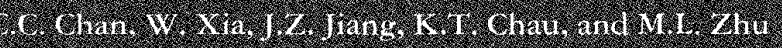

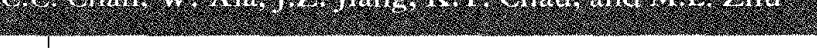

(1)

n order to fulfill the stringent requirements of modern drive systems, researchers are developWher motor drives with high efficiency, high power density and good dynamic performance. Recently, a new design concept of permanent magnet (PM) brushless motors has been developed [1]- 3$\}$. The basic to this concept is providing an independent magnetic flux path for each phase of these motors, so-called phase decoupling (PD) PM brushless motors.

Due to phase decoupling, these PM brushless motors possess several distinct advantages over their conventional counterparts-reduction of magnetic yoke, reduction of winding overhang, minimization of cogging torque, and improvement of controllability [1]. Moreover, they can be implemented as various topologies such as rectangular fed (brushless DC), sinusoidal fed (brushless $A C)$, surface magnet, interior magnet, inset magnet, inner rotor, and outer rotor alternatives.

Because of their high power density, high efficiency and high controllability, these PD PM brushless motors have been successfully applied to experimental electric vehicles (EVs) [2]. However, similar to conventional PM brushless motors, they suffer from the loss of current regulation during high speed constant power operation. It should be noted that a wide range of constant power operation is highly desirable for $\mathrm{EV}$ applications because it can minimize the required motor size, and can also facilitate high speed cruising.

By incorporating the well-known $d-q$ coordinate transformation, flux weakening control has been accepted to achieve constant power operation of PM brushless AC motor drives, including the interior magnet type with saliency, and surface magnet type without saliency [4], [5]. The reason for its inapplicability to PM brushless DC motor drives is

the fact that the corresponding waveforms are no longer sinusoidal, and thus the $d-q$ coordinate transformation becomes ill-suited. Nevertheless, an improvement of the constant power operating characteristics of PM brushless DC motor drives has been accomplished by phase shifting the inverter switch conduction intervals with respect to the induced EMF waveforms [6], [7]. However, the improvement has also been accompanied by a significant increase in torque ripples.

Very recently, a new control technique has been proposed to allow those PM brushless DC motor drives to operate in the high speed constant power region [3]. The essence of this technique is to purposely employ the transformer EMF to oppose the rotational EMF in such a way that the loss of current regulation can be avoided at high speeds. Compared with conventional flux weakening control, this approach has some distinct advantages: it can readily be applied to PM brushless DC motor drives, especially the PD types; it can be implemented without the use of $d-q$ coordinate transformation, and it possesses low torque ripples throughout the high speed constant power region.

Although those PM brushless motor drives inherently possess high efficiency, their system efficiency can be further improved by a number of sophisticated control techniques such as in [8] and [9]. For EV applications, optimal efficiency control is particularly important because the energy resource is limited by the on-board batteries. The purpose of this paper is to present an optimal efficiency control scheme for constant power operation of those PD PM brushless DC motor drives. The key is to adaptively adjust the advanced conduction angle to minimize the system losses for a given operation point in the constant power region.

The authors are with the Department of Electrical and Electronic Engineering, University of Hong Kong, Pokfulam Road, Hong Kong. Chan is a Fellow of the IEEE, Chan is a Member. This article appeared in its original form at the APEC 96 meeting. 
In the next section, the strategy for constant power operation of PD PM brushless DC motor drives is exemplified using a 5-phase 22-pole PD PM brushless DC motor. In the sections that follow, the newly-developed optimal efficiency control technique is then illustrated. Then, after describing the corresponding implementation, both compurer simulation and experimental results are presented, and some conclusions are offered.

\section{Constant Power Operation}

A 5-phase 22-pole PD PM brushless DC motor is used for exemplification. Since its mutual inductance is practically eliminated and its winding resistance is negligible, the voltage equation of this motor can be expressed as:

$v_{j}\left(\omega t+\theta_{n}-\frac{(j-1) \pi}{5}=\right.$
$L \frac{d i_{j}\left(\omega t+\theta_{0}-\frac{(j-1) \pi}{5}\right)}{d t}+e_{j}\left(\omega t+\theta_{"}-\frac{(j-1) \pi}{5}\right)$

where $v_{j}$ is the applied voltage, $L \cdot d i j / d t$ is the transformer EMF, $e$, is the rotational EMF, $i_{i}$ is the phase current, $\omega$ is the angular frequency, $\theta_{0}$ is the advanced conducion angle, and $j=1, \ldots, 5$.

When the motor operates in the high speed constant power region, the rotational EMF becomes larger than the applied voltage. To prevent saturation of the current regulator, a negative transformer EMF is needed to oppose the rotational EMF. This negative transformer EMF is produced by advancing the conduction angle, namely, between the phase current and rotational EMF. Typical waveforms of $v_{j}, e ;, L \cdot d i j / d t$ and $i_{j}$ are shown in Fig. 1. In the interval 1-2, the applied voltage is larger than the rotational EMF so that the phase current increases and reaches its highest value. In the interval 2-3, the asplied voltage is smaller than the rotational EMF. Thus, the phase current begins to decrease and a negative transformer EMF is therefore produced. Since this negative transformer EMF opposes the rotational EMF, constant power operation becomes achievable even at high speeds. Due to symmetry, the corresponding operation in another half cycle is similar.

It should be noted that the idea of using the transformer EMF does not restrict one to any particular current shapes, and provides a general tool for the formulation of motor current and torque during constant power operation. Theoretically, the corresponding maximum operating speed of the motor occurs at $\theta_{0}=90^{\circ}$. In fact, the practical operating limit is governed by the transformer EMF, hence it is dictated by the motor inductance and operating frequency. Moreover, the cogging torque of the motor is minimized by using a unique fractional number of slots per pole per phase. At any operating point, the phase current is always synchronous with the corresponding rotational EMF. As the motor torque is developed by the interaction of the phase current and rotational EMF, this motor can provide a minimum torque ripple throughout the operating range.

\section{Optimal Efficiency Control}

By neglecting the existence of core loss or assuming that the core loss is constant, the motor drive can operate at optimal efficiency when the copper loss is minimum. The minimization of copper loss is generally accomplished by adopting the maximum torque per ampere approach. However, this approximation, negligible or con-

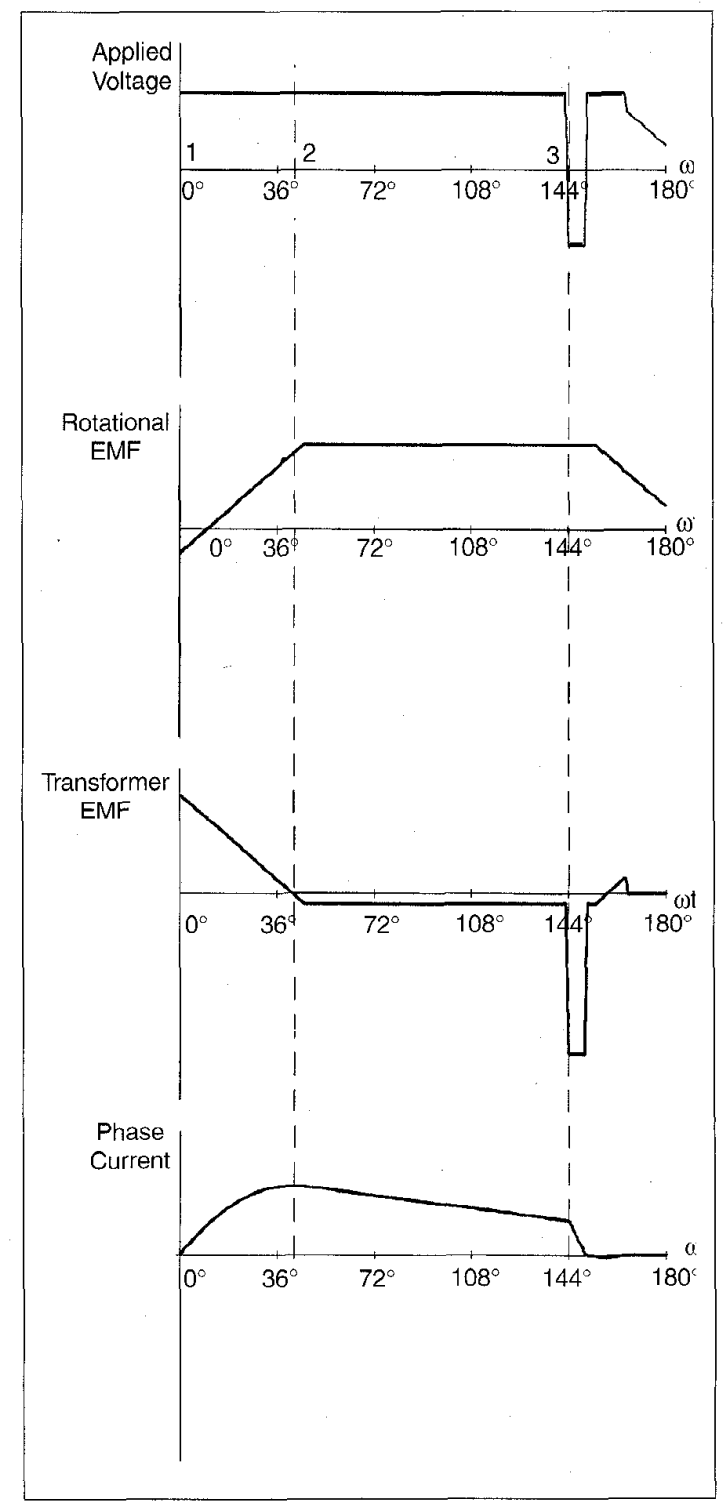

Fig. 1. Waveforms during constant power operation.

IEEF Industry Applications Magazine - November/December 1998 


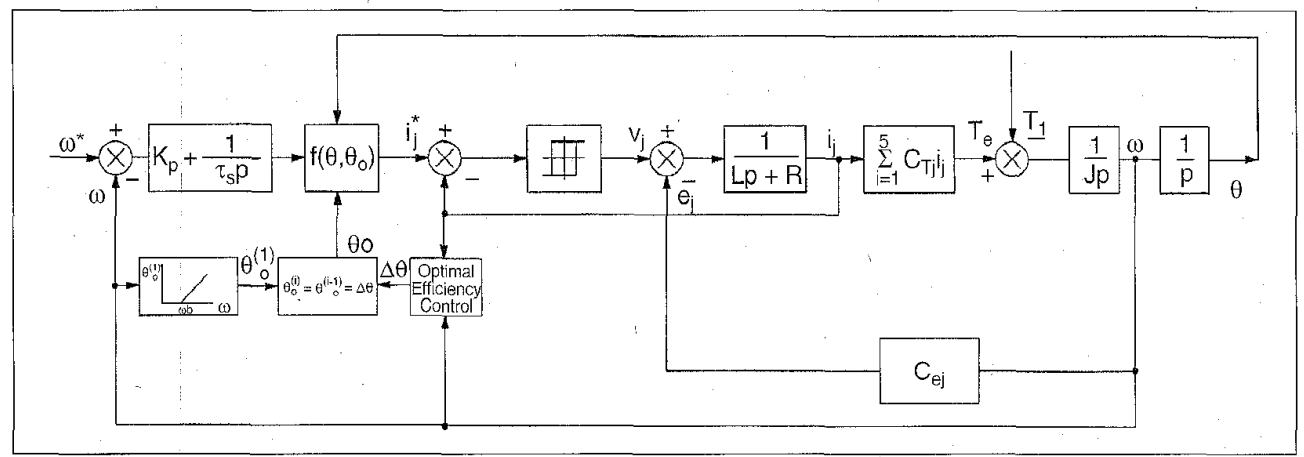

Fig. 2. Control block diagram.

stant core loss, can no longer be acceptable for high performance motor drives. In order to achieve optimal efficiency control during constant power operation, a new technique is developed which can optimize the system efficiency of the whole drive system.

The proposed optimal efficiency control scheme is to adaptively adjust the advanced conduction angle in such a way that the input power is minimum for a given output power. For this 5-phase PD PM brushless DC motor, each phase winding conducts $144^{\circ}$ over a half cycle, and the phase shift between adjacent phases is $36^{\circ}$. Thus, each phase current can be posirive, negative or zero. A positive phase current indicates that the current flows from the top of the upper half voltage source $V_{u}$ to the mid-point of the whole voltage source, while a negative phase current means that the current is from the midpoint to the bottom of the lower half voltage source $V_{l}$. For example, when $i_{1}, i_{2}, i_{3}$ are positive and $i_{4}, i_{5}$ are negative, the input power equals $\left(i_{1} V_{u}+i_{2} V_{n}+\right.$ $\left.i_{3} V_{11}+i_{4} V_{1}+i_{5} V_{l}\right)=\left(i_{1}+i_{2}+i_{3}+i_{4}+i_{.5}\right) V$ because both $V_{u}$ and $V_{l}$ are equal to a constant voltage $V$. For other sets of phase currents with different polarities, the resulting input power is the same. Thus, regardless of whether the polarity of these phase currents is positive, negative or zero, the summation of their magnitudes is directly proportional to the input power. Therefore, for a given output power, the minimization of the summation of all phase currents is equivalent to the optimization of efficiency for the whole drive system. Since the phase currents have already been measured as the feedback for the hysteresis current controller, the input power can be easily on-line calculated by summing the measured magnitudes of all phase currents.

The closed loop control block diagtam for optimal efficiency control of the motor drive is illustrated in Fig. 2. The optimal efficiency control block on-line generates the required change of advanced conduction angle $\Delta \theta$ to adaptively modify the previous $\theta_{0}$. The corresponding initial value $\theta_{o}^{(1)}$ is determined by the model shown in Fig. 3.

When the motor speed $\omega$ is lower than the base speed $\omega_{b}$ (i.e., numerically $n$ is less than $500 \mathrm{rpm}$ ),

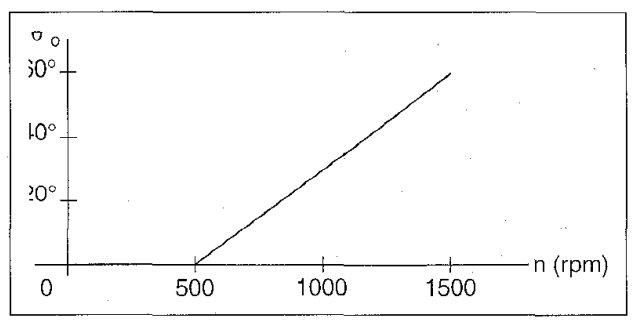

Fig. 3. Model of initial advanced conduction angle.

$\theta_{0}^{(1)}$ is always set to zero. As the motor operates above $\omega_{b}$ for constant power operation, the value of $\theta_{0}^{(1)}$ is governed by a linear relationship with the motor speed. To facilitate the generality, the slope of the line is chosen in such a way that constant power operation can be guaranteed over the desired high speed range.

The algorithm for the proposed optimal efficiency control approach is illustrated using the flowchart shown in Fig. 4. Once an interruption occurs, the motor speed $\omega$ is compared with the speed command $\omega^{*}$. If the difference is larger than a predefined experimental tolerance $k_{1}$, it indicates that the steady state has not been reached and no modification is necessary, namely $\Delta \theta=0$. Otherwise, the summation of the magnitudes of all phase currents is carried out, which stands for the new input power $W_{\text {new. }}$. Comparing it with the previous input power $W_{\text {old }}$, the difference $\Delta W$ is checked with another predefined experimental toletance $k_{2}$. If $\Delta W$ is within the tolerance, $\Delta \theta$ is set to zero. Otherwise, there are two possible actions. If $W$ new has increased, the searching direction is reversed by inverting the sign of $\Delta \theta$. If $W_{\text {new }}$ has decreased, the search continues with the same $\Delta \theta$.

A typical searching trajectory of $\theta_{0}$ for optimal efficiency operation is shown in Fig. 5. For a particular steady state operating point in the constant power region, $\mathrm{X}$ is determined from the model of $\theta_{0}^{(1)}$ shown in Fig. 3. Based on the adaptive searching algorithm shown in Fig. 4, $Y$ is reached where the input power, equivalent to the summation of the magnitudes of all phase currents, is minimum. 


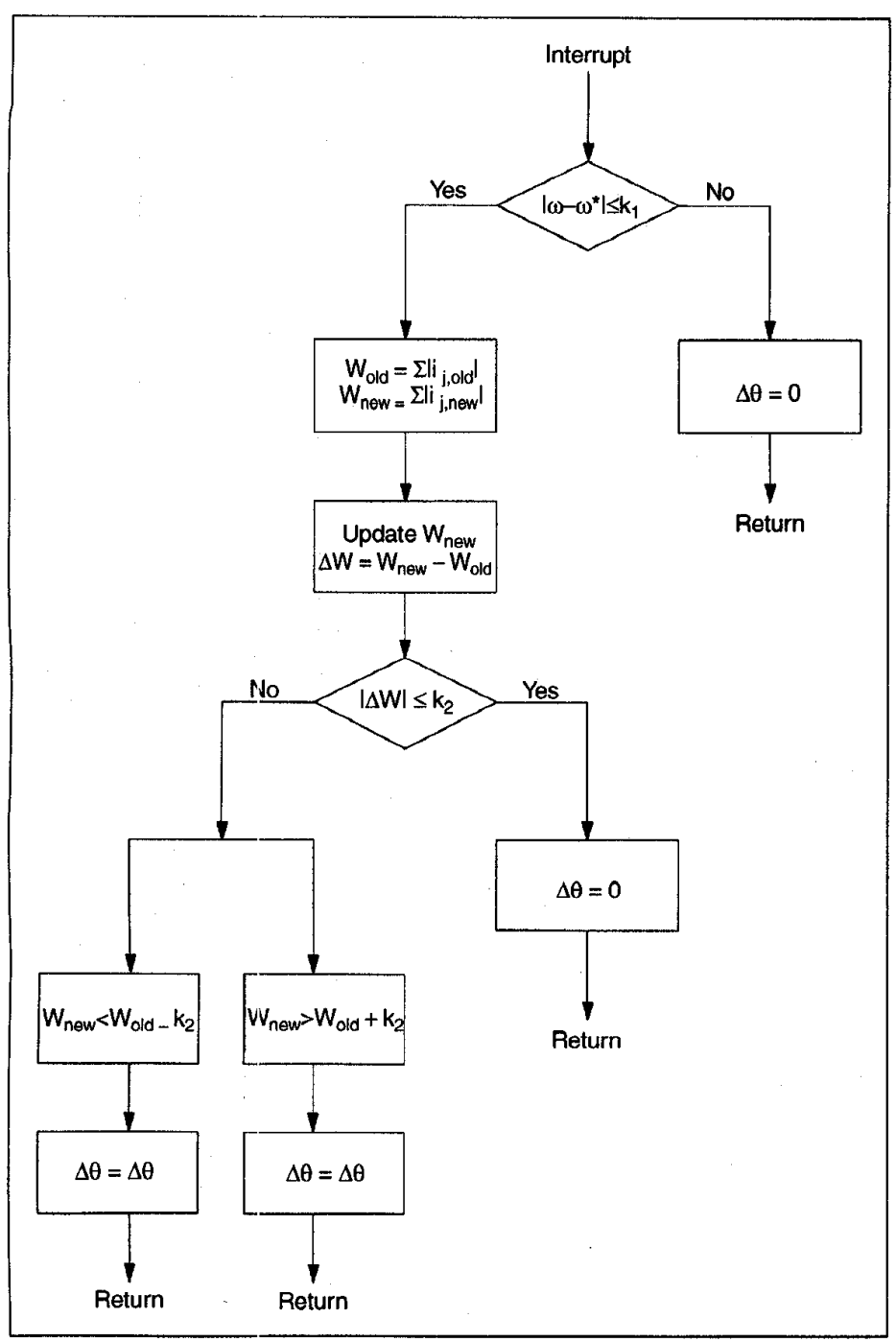

Fig. 4. Flowchart of optimal efficiency control.

It should be noted that the proposed optimal efficiency control approach does not depend on a complicated loss model of the motor. Because of its adaptive on-line search, the approach is also insensitive to variations in the motor parameters and operating environments, such as winding resistance, windage and friction, and temperature changes.

Apart from achieving optimal efficiency control during constant power operation, the torque ripple should also be kept minimum. Fig. 6 illustrates the instantaneous torque at the speed of $1500 \mathrm{rpm}$, three times the base speed, where the necessary advanced conduction arigle is $52^{\circ}$. It can be seen that the corresponding torque ripple is less than $13 \%$ of the reference value, which is actually the worst case throughout the whole speed range. In [7], the surface magnet and inset magnet brushless DC motors respectively exhibited high torque ripples of about $144 \%$ and $125 \%$ (both fluctuating between nega- conduction angle $\theta_{i n i}$ and the optimal efficiency angle $\theta_{o p t}$ is carried out. The evaluation results throughout the whole constant power operating region are shown in Fig. 7. It can be seen that the total input current and hence the input power can be significantly reduced by adaptively adjusting $\theta_{0}$ to $\theta_{o p t}$.

\section{Implementation}

The hardware implementation of the optimal efficiency controller for the proposed motor drive is illustrated in Fig. 8. A powerful single-chip microcontroller (Intel $80 \mathrm{C} 196 \mathrm{KC}$ ), is adopted to implement all necessary control functions. This microcontroller possesses built-in ROM/EPROM, RAM, high-speed inputs (HSI), high-speed outputs (HSO), A/D converter with sample/hold $(\mathrm{ACH}), \mathrm{I} / \mathrm{O}$ ports, PWM output, timers, up/down counter with capture, full duplex serial port, interrupt sources, etc. 
As shown in Fig. 8, an optical incremental position encoder is mounted on the motor shaft to generate three pulse trains, namely signals, $P_{1}, P_{2}$, and $Z$. These signals are then fed into the HSI of the microcontroller to calculate the motor speed. Motor phase currents are sensed by Hall-effect transducers and the corresponding analog signals are fed into the microcontroller via the $\mathrm{ACH}$, and the hysteresis current controller (HCC). Based on these speed and current feedback signals, the $\theta_{0}$ generator produces the corresponding advanced conduction angle, which is then outputted as a logic signal via the HSO. According to the error between the speed command $\omega^{*}$ and the speed feedback, the proportional-integral $(\mathrm{PI})$ regulator generates the current reference signals $i ;$ for the HCC. Incorporating both logic signals from the HSO and HCC, the switching signal generator produces proper

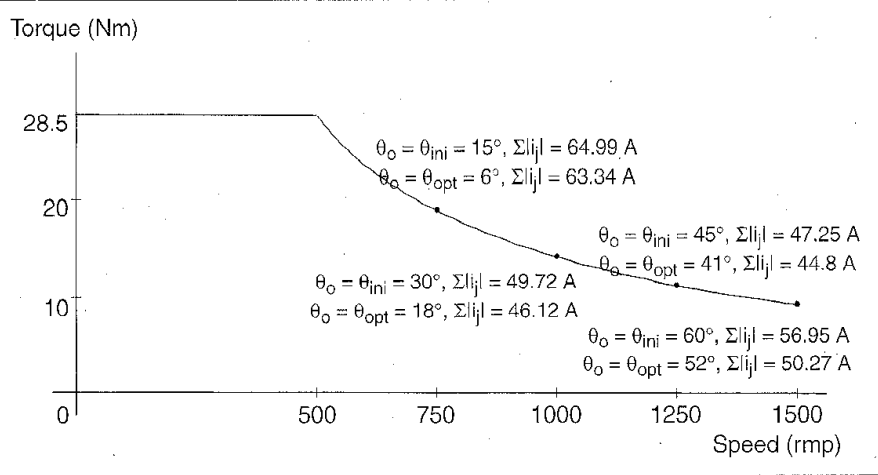

Fig. 7. Comparison between initial and optimal operations.

switching signals $T_{1}, T_{2}, T_{3}, T_{4}, T_{5}$ for the 5 -phase inverter. This inverter consists of 10 sets of power switching devices, and is supplied by a DC voltage source with a mid-point terminal.

\section{Results}

Both computer simulation and experimental results are given to illustrate the proposed approach. The technical data of the experimental motor is

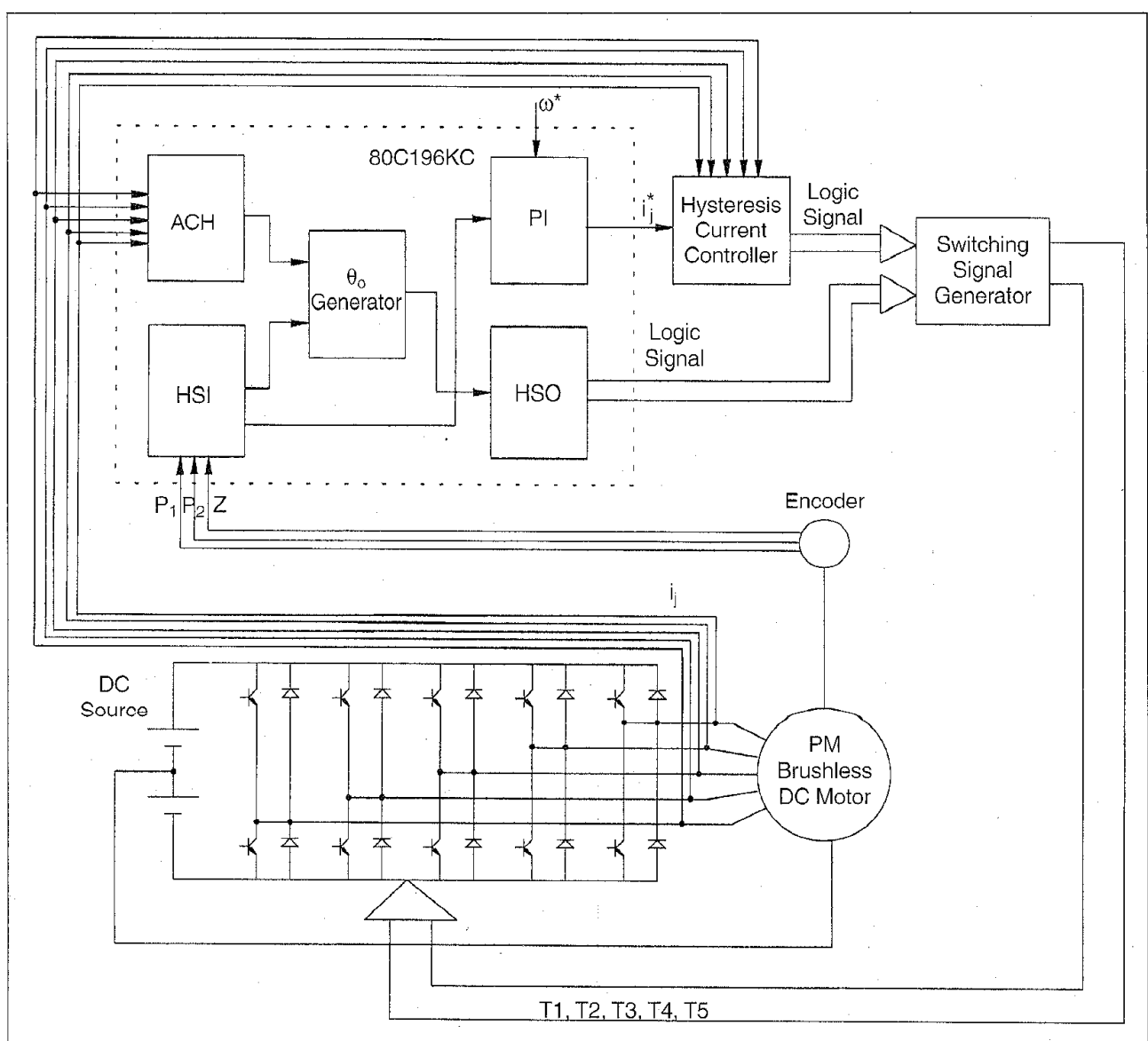

Fig. 8. Hardware implementation. 


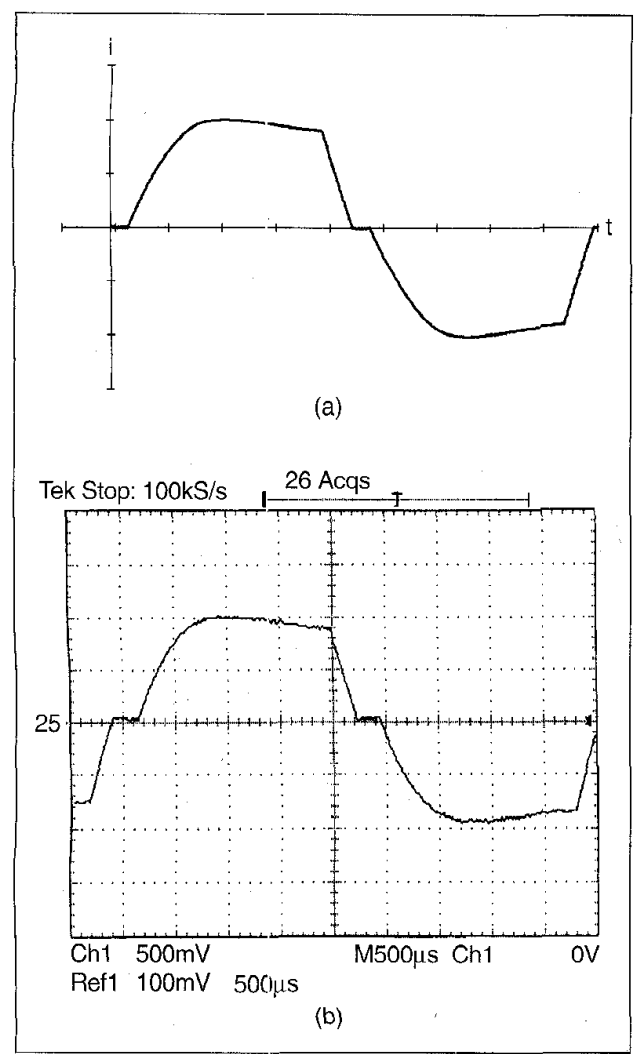

Fig. 9. Current waveforms at $1200 \mathrm{rpm}(10 \mathrm{~A} / \mathrm{div}$, 500 s/div). (a) Simulation. (b) Experimental.

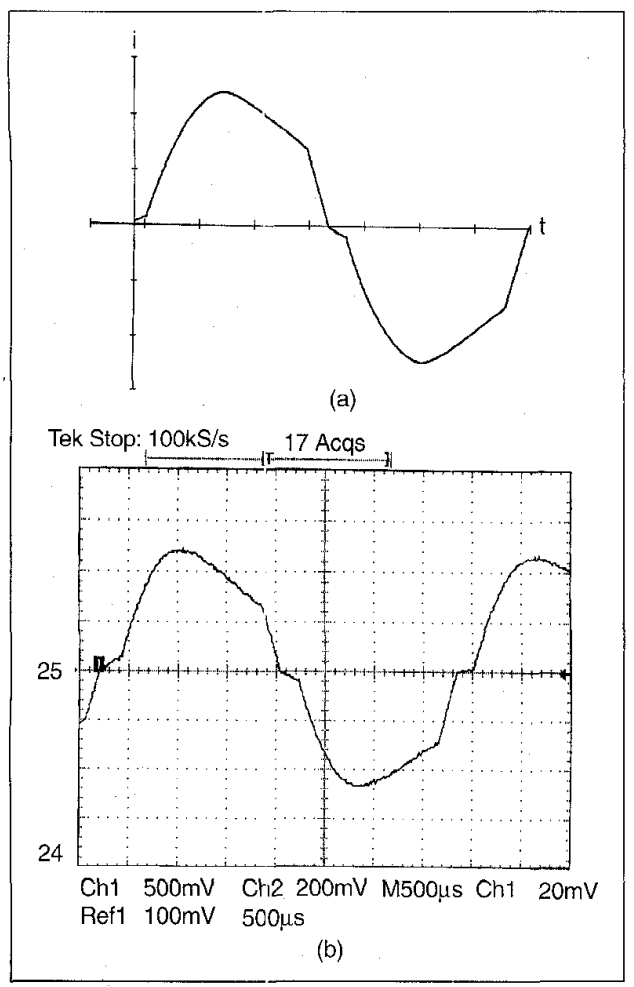

Fig. 10. Current waveforms at $1500 \mathrm{rpm}(10 \mathrm{~A} / \mathrm{div}$, 500 s/div). (a) Simulation. (b) Experimental.

\begin{tabular}{|c|c|}
\hline Ruted power & $1.5 \mathrm{~kW}$ \\
\hline Rated voltrage & $2 \times 48 \mathrm{~V}$ \\
\hline Rated speed & $500 \mathrm{rpm}$ \\
\hline Rated phase current & $26 \mathrm{~A}$ \\
\hline Number of phases & 5 \\
\hline Class of insulaton & E \\
\hline Winding type & Single layer \\
\hline Number of poles & 22 \\
\hline Number of slots & 20 \\
\hline Number of coils & 10 \\
\hline Turns per coil & 26 \\
\hline Sloi pitch & $1-2$ \\
\hline Stator outer diameter & $175 \mathrm{~mm}$ \\
\hline Rotor outer diameter & $84 \mathrm{~mm}$ \\
\hline Stutor inner diameter & $86 \mathrm{~mm}$ \\
\hline Rotor inner diameter & $48 \mathrm{~mm}$ \\
\hline Core length & $100 \mathrm{~mm}$ \\
\hline Slot width & $7.4 \mathrm{~mm}$ \\
\hline Slot height & $36 \mathrm{~mm}$ \\
\hline
\end{tabular}

listed in Table 1. Since the motor current is the most important parameter to illustrate the operating principle, the simulated and experimental current waveforms at the motor speed of $1200 \mathrm{rpm}$, torque of $11.88 \mathrm{Nm}$ and advanced conduction angle of $40^{\circ}$ are shown in Fig. 9(a) and (b), respectively. On the other hand, those waveforms at 1500 $\mathrm{rpm}, 9.8 \mathrm{Nm}$ and $58^{\circ}$ are shown in Fig. 10. Good agreement between these simulated and experimental waveforms verifies that the proposed approach works well during constant power operation.

Moreover, it can be found that the negative slope of the interval 2-3 (defined in Fig. 1) of the waveform shown in Fig. 9 is smaller than that shown in Fig. 10. This negative slope effectively causes the transformer EMF to oppose the rotational EMF during high speed constant power operation. Thus, the higher the motor speed is desired for constant power operation, the larger the advanced conduction angle is required, the steeper the negative slope of the current waveform is resulted, hence the higher the transformer EMF is generated. As shown in Fig. 10, the corresponding negative slope allows for further increase, which indicates that the speed limit for constant power operation can be further extended, beyond three times the base speed.

\section{Conclusion}

A new optimal efficiency control approach for constant power operation of a PD PM brushless DC motor drive is proposed and implemented. Since the proposed approach is so general, ic can readily be extended to other PM brushless DC and AC motor drives. The approach possesses some distinct advan- 


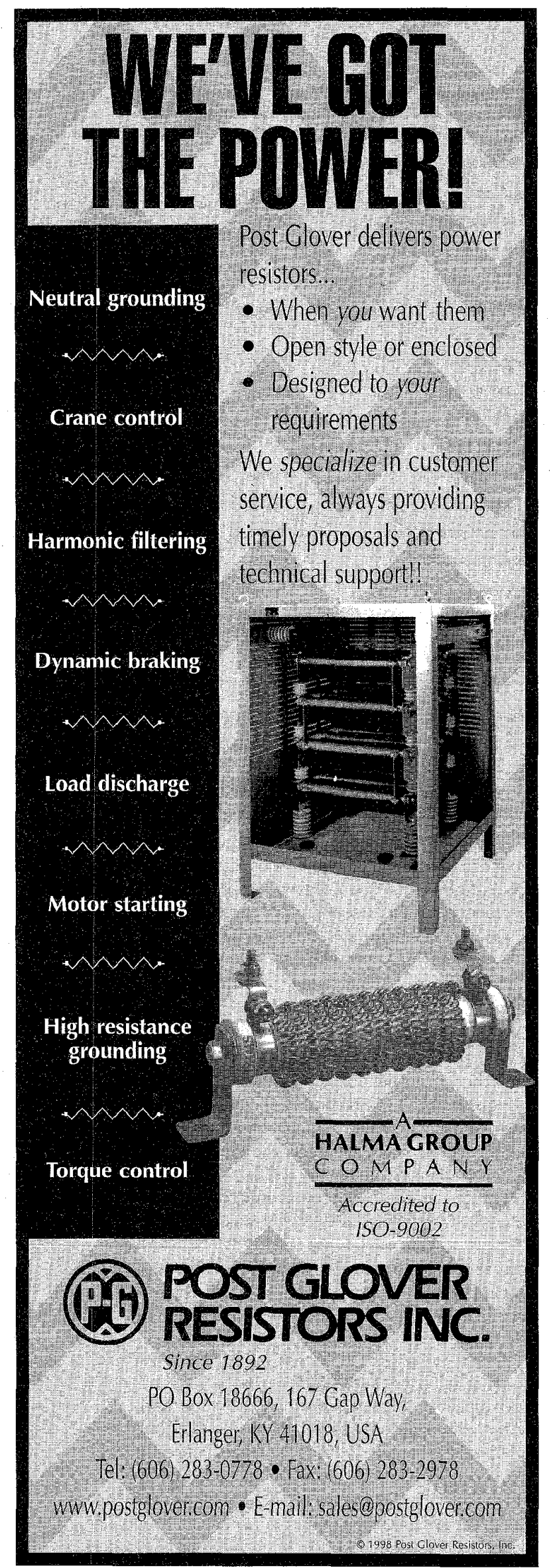

tages: it optimizes the system efficiency of the motor drive; it does not require a complicated loss model; it is insensitive to system parameter variations; and it maintains constant power operation with low torque ripples.

\section{References}

[1] C.C. Chan, J.Z. Jiang, G.H. Chen and K.T. Chau, "Computer simulation and analysis of a new polyphase multipole motor drive," IEEE Trans. Ind. Electron., vol. 40, 1993, pP. 570-576.

[2] C.C. Chan, J.Z. Jiang, G.H. Chen, X.Y. Wang and K.T. Chau, "A novel polyphase multipole square-wave permanent magnet motor drive for electric vehicles," IEEE Trans. Ind. Applicat., vol. 30, 1994, pp. 1258-1266.

[3] C.C. Chan, J.Z. Jiang, W. Xia and K.T. Chau, "Novel wide range speed control of permanent magnet brushless motor drives," IEEE Trans. Porwer Electron., vol. 10, 1995, pp. 539-546.

[4] T.M. Jahns, "Flux-weakening regime operation of an interios permanent-magnet synchronous motor drive," IEEE Trans. Ind. Applicat., vol. 23, 1987, 681-689.

[5] S. Morimoro, Y. Takeda, TT. Hirasa and K. Taniguchi, "Expansion of operaring limits for permanent magner motor by current vector control considering inverter capacity," IEEE Trans. Ind. Applicat, vol. 26, 1990, pp. 866-871.

[6] T.M. Jahns, "Torque production in permanent-magnet synchronous motor drives with rectangular current excitation," IEEE Trans. Ind. Applicat., vol. 20, 1984, pp: 803-813.

[7] N. Schofield, P.H. Mellor and D. Howe, "Field-weakening of brushless permanent magnet motors for application in a hybrid-electric vehicle," In Proc. 11th Int. Electric Vehich Symp, 1992, no. 8.13, pp. 1-11

[8] R.S. Colby and D.W. Novotny, "An efficiency-optimizing permanent-magnet synchronous motor drive," IEEE Trans Ind. Applicat., vol. 24, 1988, pp. 462-469.

[9]. S. Morimoto, Y. Tong, Y. Takeda and T. Hirasa, "Los minimization control of permanent magnet synchronous motor drives," [EEE Trans, Ind. Electron, vol. 41, 1994, pp $511-517$.

You can now get Advertising Rates for Industry Applications Magazine and other IEEE magazines via the World Wide Web

Visit us @

http://wnw.ieee.org/ magazines 